\title{
Reviews. Progress and challenges
}

\section{HORIZONTAL AND VERTICAL BIOLOGICAL AND BIO SOCIAL EFFECTS OF INCREASED IONIZING RADIATION AS EXAMPLIFIED BY CHERNOBYL AND FUKUSHIMA NUCLEAR ACCIDENTS}

(review)

\author{
V.I. GLAZKO1, 2, B.L. ZYBAILOV ${ }^{3}$, T.T. GLAZKO1, 2 \\ ${ }^{1}$ K.A. Timiryazev Russian State Agrarian University-Moscow Agrarian Academy, 49, ul. Timiryazevskaya, Mos- \\ cow, 127550 Russia; \\ ${ }^{2}$ Center for Experimental Embryology and Reproductive Biotechnology, Federal Agency of Scientific Organi- \\ zations, 12/4, ul. Kostyakova, Moscow, 127422 Russia, e-mail vglazko@yahoo.com, tglazko@rambler.ru; \\ ${ }^{3}$ University of Arkansas for Medical Sciences (UAMS), Little Rock, AR, 72205 USA \\ Received January 14, 2016
}

\section{Abstract}

In the review, our own studies of increased ionizing radiation effects on agricultural animals (nutria, rabbits, pigs, cattle) and small rodents of bio-indicator species after Chernobyl NPP accident are compared with published data of human populations' survey after the accidents at Chernobyl and Fukushima nuclear power plants. Similarity is noted of main targets for ionizing radiation (the cardiovascular system and kidneys) identified in humans and agricultural animals. Effects of ionizing radiation and post-traumatic syndromes are also comparable. Biomarkers of damages caused by ionizing radiation are considered. Differences in the estimates of the thyroid gland papillary carcinoma frequency after nuclear accidents at Chernobyl and Fukushima NPPs are discussed. Apparently, this inconsistency is mainly due to genogeographic factors, iodine deficit in geochemical province, and natural selection affecting number of generations in the populations from naturally radioactive provinces or under enhanced radionuclide pollution after technological accidents (T.I. Bogdanova et al., 2015; V.M. Drozd et al., 2015; M.B. Zimmermann, V. Galetti, 2015). A nonlinear dependency of biological effects of irradiation in the low dose range was analyzed with its possible mechanisms discussed (i.e. damage accumulation until the level necessary to induce DNA reparation, changes in young to old cell proportion in the populations, mitochondrial dysfunction) (E. Markievicz et al., 2015). A concept of «horizontal» and «vertical» effects of ionizing radiation on biological objects is introduced. It was shown that in different species of rodents (Microtus arvalis, Clethrionomys glareolus), and in the laboratory mice of C57BL/6, $\mathrm{CC} 57 \mathrm{~W} / \mathrm{Mv}$, and $\mathrm{BALB} / \mathrm{c}$ lines the irradiation of bone marrow cells induced an increase of only those cytogenetic anomalies, in comparison of control groups, the increased variability of which was typical for the studied objects in a relatively clean areas. The main and, apparently, underestimated vertical consequence of raised ionizing radiation is the decrease in reproductive success of irradiated animals. Importantly, a transgenerational transmission of post-traumatic syndrome and its mechanisms, including transmission of microRNAs, the mediators of the stress response, through the spermatozoa (K. Gapp et al., 2014), changes in microbiota of parents and their children, as well as cultural inheritance are involved to explain a complexity of observed radiobiological effects and their inheritance revealed in recent years.

Keywords: NPP accident, ionizing radiation, «horizontal» and «vertical» effects, reproductive success, transgeneration transmission.

Though the Chernobyl Nuclear Rower Plant accident happened 30 years ago in May 1986, it still remains the source of radionuclides affecting people on the polluted areas with the consequences poorly prognosticated and the defense measures not studied and substantiated enough to protect people and environments [1]. Since that time, there is a great number of reports on population genetic consequences of such large-scale man-made disaster, the first to cover the entire globe. Importantly, these studies have been performed on different 
animal and plant species, and on human populations. The latter has expectedly attracted special attention of experts and the public concern. However, only the research of biological and biosocial effects of ionizing radiation and a aggregate data accumulated allows us to analyze the observed effects comprehensively and to identify the mechanisms underlying them, on the one hand, and also contributes to understanding the fundamental processes in living things under external stresses, on the other hand. Nevertheless, there still are numerous inconsistencies between the findings [2-5]. Uniform biomarkers of ionizing radiation damage seem to help in finding consensus [6]. European Network of Biological and Retrospective Dosimetry (RENEB, Germany; http://www.reneb.eu/), in particular, is expected to develop the uniform protocol for the reliable radiation dose estimation, the high-risk group identification and prognostication of diseases [7].

In particular, new ionizing radiation biomarkers are developed due to the methods for assessing mutation patterns. However, even for such seemingly reliable statements as a link between the absorbed dose of radioactive iodine and thyroid cancer, details vary. For example, according to the Ukrainian-American Registry of patients with papillary thyroid carcinoma who have received up to 18 doses of radioactive iodine from the Chernobyl accident (UkrAm), a significant increase is found in the incidence of copy number variability (CNV) of genomic DNA short fragments [8]. Based on the same register, the dependence is found between the development of carcinomas of the thyroid gland and the dose of ionizing radiation received at a young age [9]. Regardless of the dose received, the more pronounced invasive phenotype of papillary thyroid carcinomas was observed in the patients with elevated chromosomal instability [10]. In other studies, a direct relationship was not found, and, according to authors, the number of environmental factors can affect it significantly [11].

After the accident at the Fukushima-1 nuclear power plant the thyroid cancer incidence rate among 0-18 year old children of the same age and a variety of observed mutations have been analyzed. These data indicate a significant distribution of papillary thyroid cancer in the surveyed population with the pattern of identified mutations significantly different from the papillary carcinomas resulted from the Chernobyl accident [12]. According to the authors, an increased incidence of thyroid papillary carcinoma in the region is spontaneous rather then induced by ionizing radiation.

Convincing evidences are accumulated that an increased incidence of papillary thyroid carcinoma after the Chernobyl accident are more often detected in iodine-deficient areas [13]. Currently, it seems clear that in the population the effects of ionizing radiation will be directly related to the absorbed dose (i.e. less than or greater than $100 \mathrm{mSv}$ per year), ecological and geographical conditions, age, sex and genotype, and also it will differ in the generation got directly under the irradiation (horizontal effects), and in the descendants (vertical effects) [2, 14].

A special need for classification of consequences has arisen after the Fukushima-1 accident, as it became clear that, despite an increased frequency of nuclear accidents the uniform methods for diagnosis and prediction of the radioactive contamination have not yet been developed. One can only hope that an accident at the Fukushima-1 will allow us to collect and summarizes relevant observations and experimental results more successfully.

In this regard, in the present review the available data about the peculiar effect of different doses of ionizing radiation on human population, farming animals, bioindicator animal species of small rodents, some age-based and species-specific responses, as well as transfer of induced disorders from parents to offspring are summarized. 
Nonlinear responses to low ionizing radiation. The lack of a linear relationship between the actual genetic damage and low doses of ionizing radiation is known for long time though its mechanisms remained unclear. In recent years, in several studies it have been shown that this nonlinearity may be due to the DNA repairing induction only after mammalian cell exposure to a dose exceeding $100 \mathrm{mSv}$ [15-17]. A DNA doublestrand breaks (DSBs) is reported which occurs within 30 days after the animals were inoculated once with ${ }^{137} \mathrm{CsCl}$ intraperitoneally, or with a conditionally high $(1.55 \pm 0.1 \mathrm{MBq})$ and low $(200 \pm 0.3 \mathrm{kBq})$ doses of ${ }^{85} / 90 \mathrm{SrCl}_{2}$ intravenously [18]. Based on biokinetics the authors calculated that after ${ }^{137} \mathrm{CsCl}$ removal the total 30 -day dose amounted to $10 \mathrm{~Gy}$, while the total absorbed dose after ${ }^{85} / 90 \mathrm{SrCl}_{2}$ removal, as estimated by the isotope incorporation in skeleton, was from 0 to $5 \mathrm{~Gy}$ at low irradiation reaching $49 \mathrm{~Gy}$ at the high one. In this, two picks of accumulation of lymphocytes with DSBs, during first week and in 3 weeks after the radionuclide inoculation, were observed. So far as a daily absorbed radiation dose was considered small, long term damage in lymphocytes was surprising. As to authors, the firs pick is primary due to damage of mature, almost completely differentiated lymphocytes while the second one is related to prolyferation of young progeny of these damaged cells.

An increased sensitivity to genotoxic agents and decreased DNA reparation in aging cells are documented $[19,20]$. It is a constant rejuvenation of bone marrow cell population to which it seems to be due an active cell divisions and decline in cytogenetic abnormality rate found by us in 16-18month old CC57W/Mv mice exposed to 0.5-0.6 Gy per year in the experimental vivarium in the Chernobyl exclusion zone as compared to control animals of the same age [2]. Note, in 2-3-month old mice CC57W/Mv from the vivarium the rate of cytogenetic abnormalities was considerably higher while the cell division rate was lower compared to the control. But if an activated cell division and decreased number of damaged cells in old mice may be due to more rapid renewing bone marrow cell population induced by ionizing radiation, a periodic rise and decline in the percent of cytogenetically abnormal cells in $\mathrm{CC} 57 \mathrm{~W} / \mathrm{Mv}$ mice of different generations which were exposed to the same doses and kept under the same conditions in the experimental vivarium in the Chernobyl exclusion zone, still remain unclear.

Mismatch in estimation of low dose effects could also be due to dysfunction of mitochondria. Thus, a decrease in activity of mitochondrial superoxide dismutase 2 (Sod2) can lead to appearance of classical biomarkers of ionizing radiation, e.g. dicentric and ring chromosomes [21]. A decrease in its activity is reported to be involved directly in cell aging and increase of cell sensitivity to ionizing damages [22]. So a designation of DAN as the main target molecules of ionizing radiation seems not to reflect real events, and the observed effect may be due to a functional heterogeneity of mitochondria.

Besides, stresses cause genome instability in dividing cells of a multinuclear organism, affect significantly the crossing-over rates in meiosis, and transposition of mobile elements. On laboratory mice and rats, since Hans Selye's works, a deep suppression of immune function, a durable increase in blood cortical steroids level, and disorders of cell division (a triad of Hans Selye) are known as the consequences of stresses. In rats, changes in photoperiodicity, temperature and noisiness resulted in rise of peripheral blood erythrocytes with micronuclei [23]. It was shown that methylation influenced by the environment may cause genome instability and mutagenesis due to copy number variation (CNV) in short DNA fragments [24]. In living things there is a clear genetic component in variability on stress reactivity and genome instability. Particularly, a 
comparison of the micronuclei-containing cell frequency in human identical twins showed that its variability is significantly determined genetically, the same as a response to ionizing radiation detected with a micronuclei test [25].

In our study, in different small rodent (voles), and laboratory mice exposed to a total of $<1$ Gy per year in Chernobyl exclusion zone it was shown the increase in the cytogenetic abnormalities in bone marrow cells the same as are characteristic of these species and reordered in control animals which were not exposed to irradiation [26]. That is, our experiments have shown that more than 100-fold increase in the dose of ionizing radiation did not induce new variants of mutational spectra in bone marrow cells in voles and laboratory strains of mice, but only strengthens those specific to a species or lines manifestations of genomic instability that in the control conditions occur in the studied animals spontaneously. For example, there was an increased frequency of aneuploid cells in the C57BL/6 mice, metaphases with chromosomal aberrations in SS57W/Mv line, the proportion of binuclear lymphocytes in BALB/c line, the percentage of aneuploid cells in common vole (Microtus arvalis), and the proportion of metaphases with interchromosomal Robertsonian-like translocations in the bank vole (Clethrionomys glareolus).

Obviously, very special responses to ionizing irradiation will be observed in human populations, reproducing in the natural radioactive provinces $[27,28]$, or in many generations of animals in areas with high radionuclide contamination, particularly after the Chernobyl accident [26].

The horizontal effects of ionizing radiation. To date, the most comprehensive long-term survey of the impact of ionizing radiation on human health is summarized by Japanese researchers studying the effects of the atomic bombings of Hiroshima and Nagasaki and accidents at nuclear power plants, including Fukushima [29, 30].

Effects of ionizing radiation on the human body has been studied in more detail in long-term and large-scale epidemiological survey targeted to formation of a database (registry) of the Japan residents, who are he survivors of the atomic bombings of Hiroshima and Nagasaki. Due to a large amount of information, the representation of both sexes and all ages, and a wide variety of doses evaluated individually, the results on the life expectancy, oncological and nononcological diseases (Life Span Study - LSS) in the Japanese from the register is considered the most reliable information about the effect of ionizing radiation on human populations. For this reason, LSS research was fundamental to risk assessments in radiological protection system, developed by the International Commission on Radiological Protection (International Commission on Radiological Protection - ICRP, GB). Overall, the data suggest that survivors of radiation exposure have a clear excess relative risk (ERR) of cancer compared to the control groups. For all leukemias in all age groups, this figure is 3-5 times higher when the absorbed doses are about 1 Gy per bone marrow cells [31, 32]. A statistically reliable rise in the incidence of solid tumors was observed in 6-10 years at the absorbed doses of 0.1-0.2 Gy. At that, there was an increase in tumors in the bladder, breast, lung, brain, thyroid, colon, ovaries, stomach, liver, but not in pancreas, rectum, uterus, prostate, and kidney parenchyma. Multiple noncancerous diseases, mainly cardiovascular, respiratory and immune pathologies, and kidney damage, were found in the atomic bombing survivors.

In our research, using standard electrophoresis of proteins in the starch gel and histochemical staining, we compared the isozyme patters of lactate dehydrogenase (LDH), malat dehydrogenase (MDH), malic enzyme (ME) and esterases (ES) in liver, kidney, spleen, heart muscle, lymph nodes in pigs, rabbits, nutria and cattle from $30-\mathrm{km}$ Chernobyl zone of high radionuclide 
contamination, and in the control farm animals from Kiev province [25]. In the animals from the Chernobyl exclusion zone the ${ }^{137} \mathrm{Cs}$ accumulation was 7-25fold when compared to the control and reached $160 \mathrm{~Bq} / \mathrm{kg}$.

No differences in organ-specific isozyme patterns were found between nutria from experimental and control groups.

In irradiated and control pigs the LDH spectra were the same in patterns but clearly differed in the relative activity of bands. For example, the staining of the LDH bands 1-2 with the highest electrophoretic mobility was similar in both groups whereas it was much higher in band 3 in irradiated pigs compared to control pigs. No differences were found between the groups on MDH and ME patterns. However, the ES patterns of liver and kidneys in irradiated animals differed significantly. Particularly, two fast migrating bands characteristic of liver in control animals were absent in irradiated ones, while in their kidneys there was the most electrophoretically mobile ES form which was not found in the kidney of control pigs and in any other organs of both control and irradiated animals.

In irradiated rabbits, when compared to the control animals, the ES patters were not the same in different organs. Like in pigs, in rabbits exposed to ionizing radiation some minor ES bands specific to the kidneys of intact animals were absent while new ones appeared. Interestingly, the ES pattern has changed significantly in cardiac muscle. In intact rabbits, there was a characteristic isozyme pattern with a specific band of intermediated electrophoretic mobility not found in other organs. In the cardiac muscle of irradiated rabbits this band was not observed while two new bands, fast and slow migrating, appeared which were also characteristic of ES spectra in some other organs and tissues, particularly in striated muscle. Besides, in rabbits the spleen ES isozyme spectrum has also been changed, and, as in kidneys, some bands disappeared while new ones appeared.

In cattle exposed to ionizing radiation the ESs in kidneys and cardiac muscle also differed markedly from those of intact animals.

The organ specific ES patterns of irradiated cattle and pigs were reproducible in all animals in experimental groups.

Thus, these data indicate that ES spectra are most informative to study the impact of radionuclide pollution on fundamental organ-specific biochemical processes in different animal species. In all three species studied, we observed a marked change of ES isozyme spectra in kidneys of irradiated animals. Moreover, the modified ES spectrum was also observed in the liver of pigs; in the kidneys and in the cardiac muscle of cattle and rabbits, and in spleen of rabbits. These data allows to suggest that in all three species the excretory system such as kidneys (and also the liver in swine), cardiovascular system (in cattle and rabbits), and also lymphoid tissue (in rabbits) are the main target organs damaged under irradiation.

Interestingly, our results are consistent with data on organ specificity of non-cancerous human diseases for which damage was mainly found in the cardiovascular, immune system and in the kidney [33].

Noteworthy is the fact that in the study of the effects of the earthquake and increasing exposure to ionizing radiation in human populations after the Fukushima accident, the marked deviations in carbohydrate and lipid metabolism were observed in the first few days and persist for months after exposure [34]. The same character of changes after the earthquake and at higher levels of ionizing radiation is emphasized. Thus, for 3 years in Fukushima Prefecture after the earthquake and exposure to ionizing radiation the number of patients with neuro otolaringological disease complicated by depression and other mental defects has increased significantly [34, 35].

Polycythemia is found in people who were evacuated from the zone is 
elevated ionizing radiation for 2 years after the accident at the Fukushima-1, indicating significant changes in hematopoiesis [35]. The frequency of various somatic diseases was higher in liquidators in comparison with the residents of Latvia. Diseases of the nervous, digestive, cardiovascular, endocrine, respiratory and immune systems were mostly recorded at a 1.3-fold morbidity among liquidators compared to the rest of population in 1986 which reached a 10.9-fold level in 2007 [36].

A lot of evidences of non-specific health problems in people resettled from areas with elevated levels of radiation after the Chernobyl and Fukushima accidents are also accumulated. After the Chernobyl accident the mothers relocated together with children rated their health 2 times less than in the control group [37]. After the Fukushima accident almost $30 \%$ of mothers were diagnosed clinically depressed [38]. It was shown that among people who were evacuated after the nuclear disaster at the Fukushima-1, the concern about radiation risk was associated with psychological disorders [39].

The survey of liquidators even 24 years after the Chernobyl accident showed a decrease in all three indicators (physical, mental health and social well-being) used by the World Health Organization for health monitoring in human populations [40, 41]. The survey carried out in 1999-2002 evidenced of a significant increase in the incidence of thyroid tumors, as well as depression, suicidal ideation and attempts among people living in the most contaminated regions of Ukraine [42].

The damaging effects of ionizing radiation on the brain and cognitive functions are known for a long time. Thus, A.I. Nyagu and K.N. Loganovskii [43] historically summarize the observations of the neurophysiological effects of ionizing radiation in humans which were first described in 1896. In the postChernobyl period they also reported about multiple abnormalities in the central nervous system associated with radionuclide contamination after the Chernobyl accident $[44,45]$. Evidences are being accumulated on a significant contribution of an oxidative stress, including a decrease in superoxide dismutase activity in the mitochondria, to the neurophysiological disorders induced by ionizing radiation $[46,47]$.

Additionally, a detailed study of public health after the earthquake of 2011 in Japan in different regions shows that a decrease in the objectively and subjectively assessed health indicators closely depends on the strength of the earthquake and the remoteness from its epicenter [48]. Note, the fact of resettlement from the territory with elevated levels of ionizing radiation around the Fukushima-1 nuclear power plant could itself lead to an increase in mortality among the evacuated population, and this was clearly detected during the first 4 years after the accident [49]. Moreover, an increased mortality was not directly related to the dose of external and internal exposure. It is assumed that this effect is due to post-traumatic syndrome which provokes non-specific, especially chronic, diseases rather than to actual damaging effect of ionizing radiation.

Vertical damage induced by ionizing radiation. From our point of view, the main and underestimated «vertical» consequence of exposure to ionizing radiation for living things is a reduced reproductive function with elimination of individuals possessing alleles and gene systems associated with relatively increased radiosensitivity. It is this limitation of reproduction that explains an increase in the number of radioresistant individuals among the trapped voles and the shift of the genetic structure in progeny of irradiated specialized dairy cattle toward more primitive forms described in Chernobyl exclusion zone [26], and also an increased radioresistance of blood cells in the inhabitants of the radioactive provinces. The observed changes correspond to the 
statement of I.I. Schmalhausen that under any environmental changes the most stable but the least specialized forms possess a privilege in reproduction [50].

The negative impact of post-traumatic syndrome on health is widely studied in recent years. There is evidence suggesting that increased sensitivity to stressors is observed in children born from parents with this syndrome. In Denmark in 4-9 year old children which were not subjected to injury, but born in refugee families where the post-traumatic symptom was diagnosed in one or both parents, the transmission of this syndrome has been found [51]. The manifestations of post-traumatic stress syndrome in children born from parents who survived the Holocaust were being studied for more than 50 years [52]. It was found that among the people resettled after the Fukushima accident, and among the grandchildren of Japanese survivors of the Hiroshima and Nagasaki atomic bombings the frequency of the post-traumatic stress syndrome manifestations increased relative to the control group [53]. Detailed studies are being conducted on transmission mechanisms of hypersensitivity to the expression and the induction of post-traumatic syndrome symptoms in generations, and the dependence of this phenomenon on the cultural characteristics and closeness of contacts between parents and children has been revealed [54].

People are subjected to many stress factors adversely affecting health, depressing the immune system, increasing susceptibility to infection and the risk of many other diseases. Stress can cause genetic, epigenetic and genotoxic changes in humans and animals. Ionizing radiation, as is known, may also induce the whole range of such changes. But so far the combined effect of stress factors and ionizing radiation remain poor studied. In rare works, there were the attempts to separate the effects of stress and ionizing radiation. In one of these studies the authors showed that in linear mice it was possible to separate the effects of stress from the damaging effects of ionizing radiation (55).

Note that the actual accidents at the nuclear power plants are always accompanied by the combined effect of a stress factors, and ionizing radiation. The Chernobyl disaster demonstrated that its psychosocial consequences are quite long-term.

Possible mechanisms for transgenerational effects of ionizing radiation. Transmission of changes caused by environmental factors, from a parent to further generation is described in several studies [56, 57].

In human and model species such as laboratory linear mice and rats, the various mechanisms of epigenetic variability affecting genomic reprogramming in gametes have bee described. These are a hormonal control of DNA methylation profile, changes in chromatin packaging and the histone code, an accumulation of regulatory microRNAs in the gametes that may be involved in transgenerational inheritance [58]. Induction of epigenetic changes in spermatogenesis by external factors is described in several studies [59, 60]. Thus, in male mice the traumatic stress during spermatogenesis induced an expression of certain miRNAs, which also persisted in the zygote that led to changes in behavior and metabolism in the offspring [61, 62]. This miRNA, being isolated and then introduced into normal zygote, caused the same changes in born offspring [63, 64]. In the primordial stem cells populating gonads of the embryos prenatally exposed to vinclozolin, the endocrine disregulator, there were changes in synthesis of a number of miRNAs that regulate cell differentiation [65]. To date, a large number of miRNAs are found, in which the changes in metabolism can directly contribute to epigenetic variability of offspring via the influence of the environment on the parents [66].

Another pathway of epigenetic inheritance may be associated with the intergenomic relationship between multicellular organisms and its microbiome 
(metagenomics) [67]. Multicellular organisms, such as plants and animals, are not an autonomous units, but a biomolecular networks of the host cells and associated microbiome. In opinion of some researchers, such a set of organisms may be defined as a holobionts, and their genomes are considered as hologenomes [68]. Multiple molecular mechanisms of microbiome action on the various functions of multicellular organism are revealed, including raising its epigenetic variability, and the evidence experimentally obtained on the model objects indicates that the changes in the microbiome can result in modifications of behavior $[69,70]$.

Thus, the evidence obtained to date, suggests that the transgenerational transmission of responses to environmental stress from parents to their progeny may be due to cultural inheritance (54), or result from induced epigenetic changes in the parental gametes (or in the gametes of descendants during embryogenesis), in embryos during early development, as well as in the microbiome of parents and the offspring.

So, an increase of ionizing radiation leads to multiple changes in living things, which can be divided into «horizontal» in those ones subjected to the irradiation directly, and the «vertical» detected in their offspring. In mammals, not only actively proliferating immune system, but also cardiovascular and excretory systems, as well as brain are among the main targets. Changes depend on the species, the genotypic features of exposed organisms, the region of their reproduction, the feeding, as well as on the absorbed doses, the lowest of which do not induce the intracellular reparative mechanisms thus «preserve» occurred damage for a long time. Expression of «vertical» genetic effects in population is determined by selection of radioresistant forms whereas the inheritance of posttraumatic syndrome in model organisms (linear mice) is due to the transspermal transmission of miRNAs involved in the regulation of many changes in gene systems during ontogenesis. Biosocial consequences for human populations result not only from the radiation-induced changes in central nervous system and the transmission of microRNAs involved in stress syndrome formation, but are also related to the cultural inheritance and modification of microbiome. Eexpectedly, the registers (database) of parents and their descendants of different generations, which takes into account not only the doses of ionizing radiation, but also the eco-geo-biochemical factors of habitats, and the ethnic features, will help to understand peculiarities of radiobiological response. In turn, this will speed up developing methods for diagnostics and radioprotection, and also allow to suggest techniques for targeted compensation of radiation damage in cells, organs or systems of multicellular organisms.

\section{R E F E R E N C ES}

1. Shimura T., Ya maguchi I., Terada H., Svendsen E.R., Kunugit a N. Public health activities for mitigation of radiation exposures and risk communication challenges after the Fukushima nuclear accident. Journal of Radiation Research, 2015, 56(3): 422-429 (doi: 10.1093/jrr/rrv013).

2. Glazko V.I., Glazko T.T. Sources of contradictions in the evaluation of population genetic consequences after the Shernobyl disaster. Acta Naturae, 2013, 5(1): 47-62.

3. Little M.P., Goodhead D.T., B ridges B.A., B ouffle r S.D. Evidence relevant to untargeted and transgenerational effects in the offspring of irradiated parents. Mutat. Res., 2013, 753(1): 50-67 (doi: 10.1016/j.mrrev.2013.04.001).

4. Lit l e M.P. Germline minisatellite mutations in the offspring of irradiated parents. J. Radiol Prot., 2015, 35: E1-E4 (doi: 10.1088/0952-4746/35/1/E1).

5. Pernot E., Hall J., Ba a tout S., Benotmane M.A., Blanchardon E., B ouf fler S., El Saghire H., Gomolka M., Guertler A., Harms-Ringdahl M., Jeggo P., Kreuzer M., Laurier D., Lindholm C., Mkacher R., Quintens R., Rothkamm K., Sabatier L., Tapio S., de Vathaire F., Cardis E. Ionizing radiation biomarkers for potential use in epidemiological studies. Mutat. Res., 2012, 
751: 258-286 (doi: 10.1016/j.mrrev.2012.05.003).

6. Perumal V., Sekaran T.S.G., Ra avi V., B a she erudeen S.A.S., Kanagaraj K., Chowdhury A.R., Paul S.F.D. Radiation signature on exposed cells: relevance in dose estimation. World J. Radiol., 2015, 7(9): 266-278 (doi: 10.4329/wjr.v7.i9.266).

7. Kulka U., Ainsbury L., Atkinson M., Barnard S., Smith R., Barquine ro J.F., Barrios L., B assinet C., B e inke C., Cucu A., Darroudi F., Fattibene P., Bortolin E., Della Monaca S., Gil O., Gregoire E., Had jidekova V., Haghdoost S., Hatzi V., He mpel W., Herranz R., Jaworska A., Lindholm C., Lumniczky K., M'kacher R., Mörtl S., Montoro A., Moquet J., Moreno M., Noditi M., Ogbazghi A., Oestreicher U., Palitti F., Pantelias G., Popescu I., Prieto M.J., Roch-Lefevre S., Roessle r U., Rom m H., R oth k m m K., S abatie r L., S ebastia N., S o m mer S., Terzoudi 1 G., Testa A., Thierens H., Trompier F., Turai I., Vandevoorde C., Vaz P., Vois in P., Vral A., Ugletveit F., Wieser A., Wo d a C., Wojcik A. Realising the European networkof biodosimetry: RENEB - status quo. Radiation Protection Dosimetry, 2015, 164(1-2): 42-45 (doi: 10.1093/rpd/ncu266).

8. Selmansberger M., Braselmann H., Hess J., Bogdanova T., Abend M., Tronko M., Brenner A., Zitzelsberger H., Unger K. Genomic copy number analysis of Chernobyl papillary thyroid carcinoma in the Ukrainian-American Cohort. Carcinogenesis, 2015, 36(11): 1381-1387 (doi: 10.1093/carcin/bgv119).

9. Little M.P., Kwon D., Zablotska L.B., Brenner A.V., Cahoon E.K., Rozhko A.V., Polyanskaya O.N., Minenko V.F., Golovanov I., Bouville A., Droz$\mathrm{dovit} \mathrm{ch} \mathrm{V}$. Impact of uncertainties in exposure assessment on thyroid cancer risk among persons in Belarus exposed as children or adolescents due to the Chernobyl accident. PLOS ONE, 2015, 10(10): e0139826 (doi: 10.1371/journal.pone.0139826).

10. Bogdanova T.I., Zurnadzhy L.Y., Nikiforov Y.E., Leeman-Neill R.J., Tronko M.D., Chanock S., Mabuchi K., Likhtarov I.A., Kovgan L.M., Drozdovitch V., Little M.P., Hatch M., Zablotska L.B., Shpak V.M., McConnell R.J., B re nner A.V. Histopathological features of papillary thyroid carcinomas detected during four screening examinations of a Ukrainian-American cohort. Br. J. Cancer., 2015, 113(11): 1556-1564 (doi: 10.1038/bjc.2015.372).

11. Drozd V.M., Saenko V.A., Brenner A.V., Drozdovitch V., Pashkevich V.I., Kudelsky A.V., Demidchik Y.E., Branovan I., Shiglik N., Rogounovitch T.I., Yamashita S., Biko J., Reiners C. Major factors affecting incidence of childhood thyroid cancer in Belarus after the Chernobyl accident: do nitrates in drinking water play a role? PLOS ONE, 2015, 10(9): e0137226 (doi: 10.1371/journal.pone.0137226).

12. Mitsutake N., Fukushima T., Matsuse M., Rogounovitch T., Saenko V., Uchino S., Ito M., Suzuki K., Suzuki S., Yamashita S. BRAFV600E mutation is highly prevalent in thyroid carcinomas in the young population in Fukushima: a different oncogenic profile from Chernobyl. Scientific Reports, 2015, 5: 16976 (doi: 10.1038/srep16976).

13. Zimmermann M.B., Galetti V. Iodine intake as a risk factor for thyroid cancer: a comprehensive review of animal and human studies. Thyroid Research, 2015, 8: 8 (doi: 10.1186/s13044-015-0020-8).

14. G l a z k o V.I., Glazko T.T. Laws of anthropogenic (ecological) disasters - the example of the Chernobyl accident. Biotechnol. \& Biotechnol. Equipment, 2011, 25(4): 1-6 (doi: 10.5504/bbeq.2011.0088).

15. Rothkamm K., Lobrich M. Evidence for a lack of DNA double-strand break repair in human cells exposed to very low X-ray doses. PNAS USA, 2003, 100(9): 5057-5062 (doi: 10.1073/pnas.0830918100).

16. Suzuki K., Yamashita S. Low-dose radiation exposure and carcinogenesis. Jpn. J. Clin. Oncol., 2012, 42(7): 563-568 (doi: 10.1093/jjco/hys078).

17. Markiewicz E., Barnard S., Haines J., Coster M., van Geel J., Wu W., Richards S., Ainsbury E., Rothkamm K., Bouffler S., Quinlan R.A. Nonlinear ionizing radiation-induced changes in eye lens cell proliferation, cyclin D1 expression and lens shape. Open Biol., 2015, 5: 150011 (doi: 10.1098/rsob.150011).

18. Turner H.C., Shuryak I., Weber W., Doyle-Eisele M., Melo D., Guilmet te R., Amundson S.A., Brenner D.J. $\gamma$-H2AX kinetic profile in mouse lymphocytes exposed to the internal emitters cesium-137 and strontium-90. PLOS ONE, 2015, 10(11): e0143815 (doi: 10.1371/journal.pone.0143815).

19. Solovjeva L., Firsanov D., Vasilishina A., Chagin V., Pleskach N., Kropotov A., Svetlova M. DNA double-strand break repair is impaired in presenescent Syrian hamster fibroblasts. BMC Mol. Biol., 2015, 16: 18 (doi: 10.1186/s12867-015-0046-4).

20. S c ot t B.R. Radiation-hormesis phenotypes, the related mechanisms and implications for disease prevention and therapy. J. Cell. Commun. Signal., 2014, 8: 341-352 (doi: 10.1007/s12079-014-0250-x). 
21. Samper E., Nicholls D.G., Melov S. Mitochondrial oxidative stress causes chromosomal instability of mouse embryonic fibroblasts. Aging Cell, 2003, 2(5): 277-285 (10.1046/j.14749728.2003.00062.x).

22. Velarde M.C., Flynn J.M., Day N.U., Melov S., Campisi J. Mitochondrial oxidative stress caused by Sod2 deficiency promotes cellular senescence and aging phenotypes in the skin. Aging (Albany NY), 2012, 4(1): 3-12.

23. Adam M.L., Torres M.F.P., Franci A.C., Sponchiado G., Torres R.A., dos Santos Correia M.T. On the stress by photoperiod, temperature and noise as possible causes of genomic damaging in an animal model. Stress Health, 2011, 27: e152-156 (doi: 10.1002/smi.1350).

24. Skinner M.K., Guerrero-Bosagna C., Haque M.M. Environmentally induced epigenetic transgenerational inheritance of sperm epimutations promote genetic mutations Epigenetics, 2015, 10(8): 762-771 (doi: 10.1080/15592294.2015.1062207).

25. Surowy H., Rinckleb A., Luedeke M., Stuber M., Wecker A., Varga D., Maier C., Hoegel J., Vogel W. Heritability of baseline and induced micronucleus frequencies. Mutagenesis, 2011, 26(1): 111-117 (doi: 10.1093/mutage/geq059).

26. Glazko T.T., Arkhipov N.P., Glazko V.I. Populyatsionno-geneticheskie posledstviya ekologicheskikh katastrof na primere chernobyl'skoi avarii [Population genetics effects of environmental disasters on the example of Chernobyl accident (in Russ.)]. Moscow, 2008.

27. Aliyu A.S., Ramli A.T. The world's high background natural radiation areas (HBNRAs) revisited: a broad overview of the dosimetric, epidemiological and radiobiological issues. Radiation Measurements, 2015, 73: 51-59 (http://www.researchgate.net/publication/270704634).

28. $\mathrm{M} ø 11 \mathrm{e} \mathrm{r}$ A.P., $\mathrm{M}$ o u s s e a u T.A. The effects of natural variation in background radioactivity on humans, animals and other organisms. Biol. Rev., 2013, 88(1): 226-254 (doi: 10.1111/j.1469-185X.2012.00249.x).

29. Hasegawa A., Tanigawa K., Ohtsuru A., Yabe H., Maeda M., Shigemura J., Ohira T., Tominaga T., Akashi M., Hirohashi N., Ishikawa T., Kamiya K., Shibuya K., Yamashita S., Chhem R.K. Health effects of radiation and other health problems in the aftermath of nuclear accidents, with an emphasis on Fukushima. Lancet, 2015, 386(9992): 479-488 (doi: 10.1016/S0140-6736(15)61106-0).

30. Kamiya K., Ozasa K., Akiba S., Niwa O., Kodama K., Takamura N., Zaharieva E.K., Kimura Y., Wake ford R. Long-term effects of radiation exposure on health. Lancet, 2015, 386(9992): 469-478 (doi: 10.1016/S0140-6736(15)61167-9).

31. Richardson D., Sugiyama H., Nishi N., Sakata R., Shimizu Y., Grant E.J., Soda M., Hsu W.-L., Suyama A., Kodama K., Kasagi F. Ionizing radiation and leukemia mortality among Japanese atomic bomb survivors, 1950-2000. Radiat. Res., 2009, 172: 368-382 (doi: 10.1667/RR1801.1).

32. Hsu W.-L., Preston D.L., Soda M., Sugiyama H., Funamoto S., Kodama K., Kimura A., Kamada N., Dohy H., Tomonaga M., Iwanaga M., Miyazaki Y., Cullings H.M., Suyama A., Ozasa K., Shore R.E., Mabuchi K. The incidence of leukemia, lymphoma and multiple myeloma among atomic bomb survivors: 1950-2001. Radiat. Res., 2013, 179: 361-382 (doi: 10.1667/RR2892.1).

33. Tsubokura M., Takita M., Matsumura T., Hara K., Tanimoto T., Kobayashi R., Hamaki T., O iso G., Kami M., Okawada T., Tachiya T. Changes in metabolic profiles after the Great East Japan Earthquake: a retrospective observational study. BMC Public Health, 2013, 13: 267 (doi: 10.1186/1471-2458-13-267).

34. H a s e gawa J., Hidaka H., Kuriyama S., Obara T., Hashimoto K., Tated a Y., O ku mura Y., Kobay a sh i T., Katori Y. Change in and long-term investigation of neuro-otologic disorders in disaster-stricken Fukushima Prefecture: retrospective cohort study before and after the Great East Japan Earthquake. PLOS ONE, 2015, 10(4): e0122631 (doi: 10.1371/journal.pone.0122631).

35. Sakai A., Ohira T., Hosoya M., Ohtsuru A., Satoh H., Kawasaki Y., Suzuki H., Takahashi A., Kobashi G., Ozasa K., Yasumura S., Yamashita S., Ka mi y K., Ab e M. Life as an evacuee after the Fukushima Daiichi nuclear power plant accident is a cause of polycythemia: the Fukushima health management survey. BMC Public Health, 2014, 14: 1318 (doi: 10.1186/1471-2458-14-1318).

36. Eglite M.E., Zvagule T.J., Rai n s ford K.D., Reste J.D., Curbakova E.V., Kurjane N.N. Clinical aspects of the health disturbances in Chernobyl Nuclear Power Plant accident clean-up workers (liquidators) from Latvia. Inflammopharmacology, 2009, 17(3): 163169 (Epub 2009 Jun 13).

37. Bromet E.J., Gluzman S., Schwartz J.E., Goldgaber D. Somatic symptoms in women 11 years after the Chornobyl accident: prevalence and risk factors. Environ. Health Perspect., 2002, 110(suppl. 4): 625-629 (http://ehpnet1.niehs.nih.gov/docs/2002/suppl-4/625629 bromet/abstract.html).

38. Goto A., Bromet E.J., Fujimori K. Immediate effects of the Fukushima nuclear 
power plant disaster on depressive symptoms among mothers with infants: a prefectural-wide cross-sectional study from the Fukushima health management survey. BMC Psychiatry, 2015, 15: 59 (doi: 10.1186/s12888-015-0443-8).

39. Suzuki Y., Yabe H., Yasumura S., Ohira T., Niwa S.-I., Ohtsuru A., Mashiko H., M a d a M., Abe M. Psychological distress and the perception of radiation risks: the Fukushima health management survey. Bull. World Health Org., 2015, 93: 598-605 (doi: 10.2471/BLT.14.146498)

40. Laidra K., Rahu K., Tekkel M., Aluoja A., Leinsalu M. Mental health and alcohol problems among Estonian cleanup workers 24 years after the Chernobyl accident. Social Psychiatry and Psychiatric Epidemiology, 2015, 50(11): 1753-1760 (doi: 10.1007/s00127-0151102-6).

41. B r o m e t E.J., L u ft B.J. Consequences of toxic disasters for rescue, recovery, and clean-up workers require integrated mental and physical health monitoring. Social Psychiatry and Psychiatric Epidemiology, 2015, 50(11): 1761-1763 (doi: 10.1007/s00127-015-1124-0).

42. Cont is G., Fole y T.P. Depression, suicide ideation, and thyroid tumors among Ukrainian adolescents exposed as children to Chernobyl radiation. J. Clin. Med. Res., 2015, 7(5): 332-338 (doi: 10.14740/jocmr2018w).

43. Nyagu A.I., Loga novski i K.N. Neiropsikhiatricheskie effekty ioniziruyushchikh izluchenii [Neuropsychiatric effects of ionizing radiation (in Russ.)]. Kiev, 1998.

44. Nyagu A.I., Loga novski i K.N. Zhurnal nevropatologii i psikhiatrii im. S.S. Korsakova, 1997, 97(2): 62-70 (in Russ.).

45. He i e rvang K.S., M ednick S., Sundet K., Rund B.R. Effect of low dose ionizing radiation exposure in utero on cognitive function in adolescence. Scand. J. Psychol., 2010, 51(3): 210-215.

46. B a lch J.E., Craver B.M., Tran K.K., Yu L., Chmielewski N., Allen B.D., L i m o li C.L. Persistent oxidative stress in human neural stem cells exposed to low fluences of charged particles. Redox Biology, 2015, 5: 24-32 (doi: 10.1016/j.redox.2015.03.001).

47. Parihar V.K., Allen B.D., Tran K.K., Chmielewski N.N., Craver B.M., Martirosian V., Morganti J.M., Rosi S., Vlkolinsky R., Acharya M.M., Nels on G.A., Alle n A.R., Li m oli C.L. Targeted overexpression of mitochondrial catalase prevents radiation-induced cognitive dysfunction. Antioxidants \& Redox Signaling, 2014, 22(1): 78-91 (doi: 10.1089/ars.2014.5929).

48. Sugimoto T., Shinozaki T., Mi ya moto Y. Aftershocks associated with impaired health caused by the Great East Japan Disaster among youth across Japan: a national crosssectional survey. Interact. J. Med. Res., 2013, 2(2): e31 (doi: 10.2196/ijmr.2585).

49. T a n a k a R. Prolonged living as a refugee from the area around a stricken nuclear power plant increases the risk of death. Prehosp. Disaster. Med., 2015, 30(4): 425-430 (doi: 10.1017/S1049023X15004926).

50. S h mal'g a u z e n I.I. Faktory evolyutsii. Teoriya stabiliziruyushchego otbora. [Factors of evolution. Stabilizing selection concept (in Russ.)]. Moscow, 1968.

51. D a lga a rd N.T., Todd B.K., D a n i e l S.I., M o n tgome ry E. The transmission of trauma in refugee families: associations between intra-family trauma communication style, children's attachment security and psychosocial adjustment. Attach. Hum. Dev., 2016, 18(1): 69-89 (doi: 10.1080/14616734.2015.1113305).

52. B r a g a L.L., M e 11 o M.F., Fik s J.P. Transgenerational transmission of trauma and resilience: a qualitative study with Brazilian offspring of Holocaust survivors. BMC Psychiatry, 2012, 12: 134 (doi: 10.1186/1471-244X-12-134).

53. B en-Ezra M., Palgi Y., S offer Y., Shrira A. Mental health consequences of the 2011 Fukushima nuclear disaster: are the grandchildren of people living in Hiroshima and Nagasaki during the drop of the atomic bomb more vulnerable? World Psychiatry, 2012, 11(2): 133 (doi: 10.1016/j.wpsyc.2012.05.011).

54. D a lga a rd N.T., M o n tg o mery E. Disclosure and silencing: a systematic review of the literature on patterns of trauma communication in refugee families. Transcultural Psychiatry, 2015, 52(5): 579-593 (doi: 10.1177/1363461514568442).

55. Wang B., Tanaka K., Katsube T., Ninomiya Y., Vares G., Liu Q., Morit a A., $\mathrm{Nak}$ a j i ma T., N e n o i M. Chronic restraint-induced stress has little modifying effect on radiation hematopoietic toxicity in mice. J. Radiat. Res., 2015, 56(5): $760-767$ (doi: 10.1093/jrr/rrv030).

56. Pe mbrey M., S affery R., B y gre $n$ L.O. Human transgenerational responses to earlylife experience: potential impact on development, health and biomedical research. J. Med. Genet., 2014, 51: 563-572 (doi: 10.1136/jmedgenet-2014-102577).

57. Grandjean Ph., Barouki P., B ellinger D.C., Casteleyn L., Chadwick L.H., Cordie r S., Etzel R.A., Gray K.A., H a E.-H., J u nien C., K a ragas M., K a w a m o t o T., L a w re n c e B.P., P e re ra F.P., Prins G.S., Pug a A., Rosenfeld C.S., Sherr D.H., Sly P.D., Suk W., Sun Q., Toppari J., van den Ha- 
z e 1 P., Walke r C.L., H e in d e 1 J.J. Life-long implications of developmental exposure to environmental stressors: new perspectives. Endocrinology, 2015, 156(10): 3408-3415 (doi: 10.1210/EN.2015-1350).

58. Trerotola M., Relli V., Simeone P., Alberti S. Epigenetic inheritance and the missing heritability. Human Genomics, 2015, 9: 17 (doi: 10.1186/s40246-015-0041-3).

59. Cas as E., Vavouri T. Sperm epigenomics: challenges and opportunities. Front. Genet., 2014, 5: 330 (doi: 10.3389/fgene.2014.00330).

60. W e ig m a $\mathrm{n}$ K. Lifestyle in the sperm. EMBO reports, 2014, 15: 1233-1237 (doi: 10.15252/embr.201439759).

61. W u H., H a u s e r R., K r a w e t z S.A., P i l s n e r J.R. Environmental susceptibility of the sperm epigenome during windows of male germ cell development. Curr. Envir. Health Rpt., 2015, 2: 356-366 (doi: 10.1007/s40572-015-0067-7).

62. Gapp K., Jawaid A., S arkies P., Bohacek J., Pelczar P., Prados J., Farine 11 i L., M is k a E., M a n u y I.M. Implication of sperm RNAs in transgenerational inheritance of the effects of early trauma in mice. Nat. Neurosci., 2014, 17: 667-669 (doi: 10.1038/nn.3695).

63. Rodge rs A.B., B a le T.L. Germ cell origins of posttraumatic stress disorder risk: the transgenerational impact of parental stress experience. Biological Psychiatry, 2015, 78(5): 307-314 (doi: 10.1016/j.biopsych.2015.03.018).

64. B a le T.L. Lifetime stress experience: transgenerational epigenetics and germ cell programming. Dialogues Clin. Neurosci., 2014, 16(3): 297-305 (http://www.dialogues-cns.org).

65. R odgers A.B., M o rga n C.P., L e u N.A., B a le T.L. Transgenerational epigenetic programming via sperm microRNA recapitulates effects of paternal stress. PNAS USA, 2015, 112(44): 13699-13704 (doi: 10.1073/pnas.1508347112).

66. Brieño-Enríquez M.A., García-López J., Cárdenas D.B., Guibert S., Cleroux E., Děd L., de Dios Hourcade J., Pěknicová J., Weber M., de 1 $\mathrm{M}$ a z o J. Exposure to endocrine disruptor induces transgenerational epigenetic deregulation of microRNAs in primordial germ cells. PLOS ONE, 2015, 10(4): e0124296 (doi: 10.1371/journal.pone.0124296).

67. Virant-Klun I., Stehlberg A., Kubista M., Skutella T. MicroRNAs: from female fertility, germ cells, and stem cells to cancer in Humans. Stem Cells International, 2016, 2016, Article ID 3984937, 17 pages (doi: 10.1155/2016/3984937).

68. A s g a ri S. Epigenetic modifications underlying symbiont-host interactions. Adv. Genet., 2014, 86: 253-276 (doi: 10.1016/B978-0-12-800222-3.00010-3).

69. B o rde nste in S.R., The is K.R. Host biology in light of the microbiome: ten principles of holobionts and hologenomes. PLOS Biol., 2015, 13(8): e1002226 (doi: 10.1371/journal.pbio.1002226).

70. Stilling R.M., B ordenstein S.R., D in an T.G., Cryan J.F. Friends with social benefits: host-microbe interactions as a driver of brain evolution and development? Front. Cell. Infect. Microbiol., 2014, 4: 147 (doi: 10.3389/fcimb.2014.00147). 